\title{
Characterization of Whey Protein Isolate Covalently Modified with Phenolic Compounds 1: Antioxidant and Antiviral Activities Ali, M. ${ }^{* *}$ and M. M. Elsharkawy ${ }^{2}$ \\ ${ }^{1}$ Department of Food Technology, Faculty of Agriculture, Kafrelsheikh University, 33516 Kafr El- Sheikh, Egypt. \\ ${ }^{2}$ Department of Agricultural Botany, Faculty of Agriculture, Kafrelsheikh University, 33516 Kafr El- Sheikh, Egypt. \\ "Email: mostafa.ali@agr.kfs.edu.eg; TEL.00201013678465
}

\section{ABSTRACT}

Although, the covalent modification of proteins with phenolic compounds has currently found great efforts, applications of these proteins are rare. Therefore, this study was planned to characterize the whey protein isolate (WP) modified with chlorogenic acid (CA) and rosmarinic acid (RA), at $\mathrm{pH} 9$ in the presence of air and at room temperature. The modified protein was evaluated as antioxidant and antiviral agent to inhibit Tobacco mosaic virus (TMV) on infected tomato plants. The WP proteins were characterized using the change in the intensity of tryptophan fluorescence and UV-Vis spectra of proteins, RP-HPLC, ultra-high-performance liquid chromatography coupled with electrospray ionization-quadrupole-time of flight-mass spectrometry (UHPLC-ESI-Q-TOF-MS) and TEAC assay. The results showed that the maximal tryptophan fluorescence intensity of modified proteins, WP-CA and WP-RA, were significantly decreased by $54.71 \%$ and $82.61 \%$, respectively. Data of ESI-MS illustrated that one or more molecules of CA and RA covalently bound to WP. Moreover, the WP modified with RA showed better antioxidant activity when compared with the unmodified WP and WP modified with CA. The antiviral results indicated that plants treated with WP, WP-CA and WP-RA had a decreased number of local lesions and virus concentration over the controls. Quantitative real-time PCR analysis revealed that the expression levels of defense related genes, $P R 1$ and phenylalanine-ammonia lyase $(P A L)$ were significantly increased in treated tomato plants compared to the control. These results indicate that the modified proteins could be used to design a wide range of food products and at the same time improve the antiviral activity against TMV, which seriously harms the tomato crop and thus the manufacture of its products.

Keywords: Whey protein isolate, chlorogenic and rosmarinic acids, covalent modification, Tobacco mosaic virus, pathogensis related genes, antiviral activity

\section{INTRODUCTION}

Whey protein isolate (WP) is one of the main whey protein products, which used at commercial scale in food industry due to its high nutritional and functional properties compared to other commercial protein sources. It has about 3 - 4 folds more bioavailable cysteine than other dietary proteins (Bucci and Unlu 2000, Walzem et al. 2002, Hall et al. 2003). WP contains $\beta$-lactoglobulin which has a molecular weight of $18.367 \mathrm{kDa}$ (A form), $18.281 \mathrm{kDa}$ (B form), $\alpha$-lactalbumin with a molecular weight of $14.175 \mathrm{kDa}$ (A form), $14.175 \mathrm{kDa}$ (B form), and bovine serum albumin with a molecular weight of $66.267 \mathrm{kDa}$ (Walzem et al. 2002, Solak and Akin 2012, Ali et al. 2013, Keppler et al. 2014).

WP can be used as carrier for bioactive substances, such as phenolic compounds, due to its ability to bind many compounds (Ali et al. 2013, Cao and Xiong 2017, Keppler et al. 2017, Ali et al. 2018). Phenolic compounds, which founds in many vegetables and fruits, have many interesting biological activities, e.g. antibacterial, antiviral, and antioxidant properties. Antimicrobial and antioxidant potentials of polyphenols against plant pathogens were recorded in different plants (Meng et al. 1996). Chlorogenic acid, one of the main active components of green coffee bean, is an ester formed between caffeic and quinic acids. While rosemary herb is a major source of rosmarinic acid, ester of 3,4-dihydroxyphenyllactic acid and caffeic acid. Several studies have stated the beneficial properties of chlorogenic acid to human health (Dalbem Rocha et al. 2012, Meng et al. 2013, Onakpoya et al. 2015). Chlorogenic acid can also exert antimicrobial activity and inhibit the growth of the human pathogenic yeast Candida albicans (Sung and Lee 2010). It has been used to reduces the severity of rose powdery mildew (Shetty et al. 2011). Additionally, systemic resistance against the bacterial pathogen Pseudomonas syringae was enhanced in transgenic tomato plants with elevated levels of chlorogenic acid (Niggeweg et al. 2004). These results have prompted us to investigate whether the modified whey protein with phenolic compounds could control Tobacco mosaic virus which causes important loses in crops, gaining insight into its mechanism of action.

Phenolic compounds are liable to oxidize at alkaline conditions in the presence of oxygen and form the reactive quinone radicals, which can react with proteins via noncovalent and covalent interactions (Rawel and Rohn 2010, Ali et al. 2013, Abd El-Maksoud et al. 2018, Karefyllakis et al. 2018). Prigent et al. (2003) and Ali et al. (2013) studied the interaction between chlorogenic acid and alphalactalbumin, lysozyme and beta-lactoglobulin proteins at alkaline condition using MALDI-TOF-MS and they reported that molecular weight of proteins was increased by 353 and 680-690 Da, which corresponding to one and two chlorogenic acid molecule. The formation of proteinpolyphenol conjugates may alter the chemical, structural, and functional properties of protein (Rawel et al. 2002, Ali et al. 2013, Gan et al. 2016, Jia et al. 2016, Cao and Xiong 2017, Abd El-Maksoud et al. 2018, Ali et al. 2018). Moreover, recent studies reported that the polyphenols and proteins behave in a synergistic manner when combined together, increasing bio-efficacy, and bioactivity the polyphenols of cinnamon, blueberry, and cranberry (Grace et al. 2013, Roopchand et al. 2013, Ahmed et al. 2014).

Tobacco mosaic virus (TMV) is one of the major viral diseases which cause stark losses in several crops around the world. Both of resistant varieties and cultural practices have been developed to control TMV. Therefore in recent years, more attention has been devoted to the alternative and safe compounds with antiviral properties in management strategies of plant viruses due to the undesirable effects of pesticides on human health and the environment (Elsharkawy et al. 2012, Elsharkawy and ElSawy 2015). Recently, the antiviral activity of milk was 
introduced in tomato, pepper and tobacco (Gillian 2005). Additionally, native WP used in other applications as antioxidant, antimicrobial, anticancer and others (Krissansen 2007, Madureira et al. 2007). While, the applications of modified proteins with phenolic compounds are rare. Therefore, the objectives of this study were to characterize the whey protein isolate (WP) modified with chlorogenic acid (CA) and rosmarinic acid (RA), and to improve the antioxidant activity of WP protein, in addition to offer effective disease management under applied conditions, also reducing environmental effects using natural and modified whey proteins to control Tobacco mosaic virus.

\section{MATERIALS AND METHODS}

\section{Materials}

Whey protein isolate (WP) was obtained from BiPRO, Davisco Foods International, Inc., Eden Prairie, US. Healthy tomato, Lycopersicon esculentum Mill (Castlerock), and tobacco, Nicotiana. tabacum var. samsun NN, seedlings and the severe strain of Tobacco mosaic virus (TMV) were obtained from Virus and Phytoplasma Department, Plant Pathology Research Institute, Agriculture Research Center, Giza - Egypt. Chlorogenic acid (CA), rosmarinic acid (RA), 2,2'-azinobis (3-ethylbenzothiazoline-6-sulphonic acid (ABTS) and 6-hydroxy-2,5,7,8-tetramethylchroman-2carboxylic acid (Trolox) were bought from Sigma-Aldrich (Seelze, Germany).

Methods

Modification of WP with chlorogenic acid (CA) and rosmarinic acid (RA)

Whey protein isolate-chlorogenic acid (WP-CA) and whey protein isolate-rosmarinic acid (WP-RA) conjugates were prepared as outlined by Cao and Xiong (2017) and Karefyllakis et al. (2018), with some changes. Whey protein $(2 \mathrm{~g})$ was solved in distilled water $(90 \mathrm{ml})$ and the $\mathrm{pH}$ of solution was adjusted to 9 . Then the solutions were stirred for at least one hour, to make sure complete dissolving, followed by adding $120 \mathrm{mg}$ of CA and RA solved in $10 \mathrm{ml}$ of ethanol. The $\mathrm{pH}$ of combinations readjusted again to 9 and was stirred at room temperature in open air for 1 day. Next, the solutions were dialyzed for 1 day against distilled water, at room temperature, then freeze - dried. All these steps were done for unmodified WP protein but without adding CA and RA.

Characterization of whey proteins modified with CA and RA

Measurement of the change in tryptophan fluorescence

The fluorescence intensities of UWP, WP-CA and WP-RA proteins were determined with a fluorescence spectrophotometer (Varian Australia PTY Ltd.). One mg of each protein was dissolved in $8 \mathrm{M}$ urea and filled in a quartz cell. The emission of samples were recorded at wavelength range of 300 to 700 (Ali et al. 2018).

Measurement of the change in the hydrophilic and hydrophobic character of proteins using RP-HPLC analysis

Two mg of UWP, WP-CA and WP-RA proteins was dispersed in one $\mathrm{ml}$ of potassium phosphate buffer (PBS, $\mathrm{pH}$ 7). RP-HPLC was accomplished by the Agilent 1100 Series HPLC and PLRP-S column (300 ̊, $8 \mathrm{~m}, 150$ x $4.6 \mathrm{~mm}$, Agilent Technologies, Santa Clara, USA). The analysis conditions were described in details by Keppler et al.(2017).

\section{UV-Vis Spectrometry Measurements}

The change in UV-Vis scan of studied proteins was measured according to Liu et al. (2015) and Karefyllakis et al. (2018) with some changes. A quartz cell was filled with the solution $(\mathrm{mg} / \mathrm{mL}$ PBS buffer $\mathrm{pH}$ 7.2) of proteins and scanned with a spectrophotometer (Genesys 10S UV-VIS, Thermo Fisher Scientific, USA) at the following conditions: room temperature, $190-600 \mathrm{~nm}$ wavelength range and $300 \mathrm{~nm} / \mathrm{min}$ scan rate with $1 \mathrm{~nm}$ data interval.

\section{UHPLC-ESI-Q-TOF-MS Analysis}

UHPLC-ESI-Q-TOF-MS analysis of proteins was achieved as designated by Keppler et al. (2014) with some modifications. One $\mathrm{mg}$ protein was dissolved in $1 \mathrm{ml}$ of $(1: 1$, acetonitrile: ultra-water) solution containing $0.1 \%$ formic acid. Chromatographic analysis was done using a Dionex UltiMate 3000 UHPLC System (Thermo Fisher Scientific, Waltham, USA) equipped with EC 125/2 NUCLEODUR C8

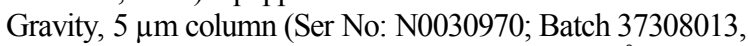
MACHEREY-NAGEL, Düren, Germany) at $30{ }^{\circ} \mathrm{C}$ with a flow rate of $0.250 \mathrm{~mL} / \mathrm{min}$. The solvents used were water (MS-Grade) containing formic acid ( $0.1 \%$, solvent A) and acetonitrile (MS-Grade) containing formic acid $(0.1 \%$, solvent $\mathrm{B}$ ). The gradient was: $0-8 \mathrm{~min}, 5-65 \mathrm{~B}$, hold for one minute, $5 \% \mathrm{~B}$ to $12 \mathrm{~min}$. The injection volume was set at $5 \mu \mathrm{L}$. The protein - phenolics conjugates were analyzed by ESI-Q-TOF mass spectrometer (micr OTOF-QII, Bruker Daltonics, Bremen, Germany). The positive Ion-Mode was used with a capillary heated at $210^{\circ} \mathrm{C}$. The source voltage was included to $4500 \mathrm{~V}$. The drying, collision and nebulizing gas was nitrogen. $6 \mathrm{~L} / \mathrm{min}$ of drying gas flow rate and nebulizer pressure at 1 par were used. Full scan data acquisition was performed from $50-3000 \mathrm{~m} / \mathrm{z}$. The exact mass results of the molecular ions were managed using the Compass Data Analysis 4.2 (Bruker Daltonics, Germany) software.

Antioxidant activities of proteins using TEAC assay

The antioxidant activities of proteins using trolox equivalent antioxidant capacity assay (TEAC) were carried out according to Re et al. (1999), with modification. $1 \mathrm{mg}$ of each protein was solved in $1 \mathrm{~mL}$ PBS buffer $(5 \mathrm{mM}$ and $\mathrm{pH} 7.2$ to 7.4 ) and vortexed for $5 \mathrm{~min}$. Next, $50 \mu \mathrm{L}$ of protein solution was added with $750 \mu \mathrm{L}$ solution of $\mathrm{ABTS}^{+}$ and kept in the dark, at room temperature, for $6 \mathrm{~min}$, after that, the absorbance of mixtures were recorded at $730 \mathrm{~nm}$ using a Helios Gamma spectrophotometer. Trolox was used to prepare calibration curve and the results are calculated as $\mu \mathrm{M}$ TE/g protein.

Induction of systemic resistance against TMV in tomato TMV inoculation

Virus inoculum was prepared by homogenizing $2 \mathrm{~g}$ of infected tobacco leaves with $0.01 \mathrm{M}$ phosphate buffer, PBS ( $\mathrm{pH}$ 7.3). The extracted sap was mechanically inoculated on the fourth leaf of each plant, which was predusted with carborundum powder (600 mesh) as previously mentioned (Elsharkawy et al. 2013).

Effect of modified proteins treatment on TMV disease severity in tomato

Tomato seedlings were transferred to new pots ( 25 $\mathrm{cm}$ diameter) filled with peaty soil. The seedlings were grown in the greenhouse $\left(22-28^{\circ} \mathrm{C}\right)$ for 2 weeks, and then treated with $5 \mathrm{~mL}$ of each WP, WP-CA and WP-RA proteins $\left(1 \mathrm{mg} \mathrm{mL}^{-1}\right)$. Control plants were treated with distilled water (DW). Two days after induction treatment, 
plants were inoculated with TMV by mechanical inoculation. Disease severity was evaluated using the following scale as described by Lian et al. (2011). Treatments were repeated 10 times.

Effect of modified whey proteins on TMV accumulation in tomato plants

TMV titre was measured using indirect enzyme linked immunosorbent assay (ELISA) (Elsharkawy and Mousa 2015). Tomato leaves were sampled at two weeks after virus challenge inoculation. Samples were ground in coating buffer (1:20) and were placed individually to ELISA plates and incubated at $4^{\circ} \mathrm{C}$ overnight. Next plates were washed 3 times with phosphate-buffered saline containing Tween-20 ( $\mathrm{pH} 7.5$, PBST). Antiserum for TMV (1:1000, SANOEL, Paris, France) was loaded onto each well followed by incubation for $1 \mathrm{~h}$ at $37^{\circ} \mathrm{C}$. Plates were washed 3 times and alkaline phosphatase (ALP) conjugated goat-anti-rabbit immunoglobulin was added to each well then incubation for $1 \mathrm{~h}$ at $37^{\circ} \mathrm{C}$. Plates were washed for 3 times and p-nitrophenyl phosphate in substrate buffer $(1 \mathrm{mg} / \mathrm{mL})$ was added. TMV titre was determined on a multiplate reader (Bio-Rad) at $405 \mathrm{~nm}$.

Assay of defense-related enzymes in tomato plants

Tomato leaves were collected at $48 \mathrm{hrs}$ after TMV inoculation and frozen in liquid nitrogen. Samples were ground in sodium phosphate buffer $(0.1 \mathrm{M}, \mathrm{pH} 7.0)$ followed by centrifugation $(10,000 \mathrm{rpm}$ for $10 \mathrm{~min})$. The crude extracts were used to measure the activities of peroxidase (POD) as described by Wang (2006), and polyphenol oxidase (PPO) as mentioned by $\mathrm{Li}$ and $\mathrm{Li}$ (1998).

\section{RT-PCR analysis}

Leaf tissues of TMV inoculated tomato plants treated with whey proteins as well as control plants were gathered at $48 \mathrm{hrs}$ post inoculation. The protocol described by Wang et al. (2009) was used to perform quantitative real time-PCR reaction. Quantitative real time-PCR was carried out using gene specific primers as shown in (Table 1). RNA was extracted following the method described by Elsharkawy et al. (2012). The normalization of target gene amount was obtained by calculating individual variations over the abundance of the constitutive Ubiquitin gene (Table 1). Quantitative RT-PCR was handled using 7500 real-time PCR system. ABI PRISM 7500 Software Tool (Applied Biosystems) was used to analyze the data. Threshold $\mathrm{Ct}$ value in $2^{-\mathrm{Ct}}$ method was calculated for the relative quantification of interested genes and introduced as a fold change of gene transcription levels. The expression levels of defense-related genes ( $P A L$ and $P R I)$ leaves were studied using real time-PCR.

Table 1. Forward and reverse primers sequence for pathogensis related genes.

\begin{tabular}{lcccc}
\hline Gene & Forward primer & Reverse primer & Size & Accession number \\
\hline LePR1 & GCCAAGCTATAACTACGCTACCAAC & GCAAGAAATGAACCACCATCC & 139 & DQ159948 \\
LePAL & CTGGGGAAGCTTTTCAGAATC & TGCTGCAAGTTACAAATCCAGAG & 150 & AW035278 \\
LeUBI3 & TCCATCTCGTGCTCCGTCT & GAACCTTTCCAGTGTCATCAACC & 144 & X58253 \\
\hline
\end{tabular}

Antiviral activity of modified whey proteins against TMV

TMV inoculum $(1 \mathrm{~mL})$ was mixed with $1 \mathrm{~mL}$ of each WP, WP-CA and WP-RA $(1 \mathrm{mg} / \mathrm{mL})$. The mixture was mechanically inoculated to Nicotiana tabacum var. samsun NN (two weeks old) pre-dusted with carborundum (600 mesh). Each treatment contains ten plants. Inoculated plants were saved in greenhouse at $25{ }^{\circ} \mathrm{C}$ for symptom development. The number of necrotic lesions was counted at 6 th days post-inoculation.

Data analysis

All data analyses were conducted using XLSTAT Pro statistical analysis software (Addinsoft, New York, NY, USA). Treatment means were compared by LSD tests at the 5\% level (Elsharkawy et al. 2012).

\section{RESULTS AND DISCUSSION}

\section{Characterization of modified proteins}

The change in the color of conjugated solution during the interactions was the first evidence for the attachment of CA and RA on WP protein. The color is changed after mixing of CA and RA with WP, where the color appeared as yellow at the first of reaction, then changed to light green and then became dark green during the reaction. The formation of brown and green colors during the interaction can be explained by the oxidation of $\mathrm{CA}$ and RA to reactive quinone radical which can react with another quinone to form brown polymerization conjugates, while in the presence the protein, the quinone interacts with it to form covalent bond (Bongartz et al. 2016, Ali et al. 2018, Karefyllakis et al. 2018). Moreover, the color formed during the interaction between RA and
WP was darker than which formed between CA and WP, this observation may be related with the number of the catechol moieties, reactive group, in each acid where, RA contains two moieties while CA have only one.

The change in tryptophan fluorescence scans of modified proteins

The change in tryptophan fluorescence intensity, as an indicator for attaching phenolics to protein, of studied proteins was determined and the results are shown in Figure (1). The data show that on excitation at $290 \mathrm{~nm}$, the unmodified WP exposed the highest fluorescence intensity at $356 \mathrm{~nm}$. On the other hand, modified WP proteins exposed a small shift in the determined emission wavelength, where, 359 and $368 \mathrm{~nm}$ was recorded for WP modified with CA and RA, respectively. This observation is in agreement with that of You et al. (2012) and Gan et al. (2016). The shift of spectra may be due to the covalent conjugation of phenolics and protein (Spizzirri et al. 2009).

As also shown in Figure (1), the maximal of fluorescence intensity of WP-CA significantly decreased by $54.71 \%$ while, $82.61 \%$ of decrease was reported for WP-RA protein. These results exposed that the interaction between RA and WP protein was higher than CA. A possibility of the interaction between phenolic compounds and tryptophan residue has been reported by Rawel et al. (2001), Rawel et al. (2002), Rawel et al. (2005), Rohn et al. (2005) and Ali et al. (2013)The quenching of fluorescence intensity can be explained by the interaction of aromatic tryptophan residues of protein with the aromatic rings of the $\mathrm{CA}$ and $\mathrm{RA}$. 


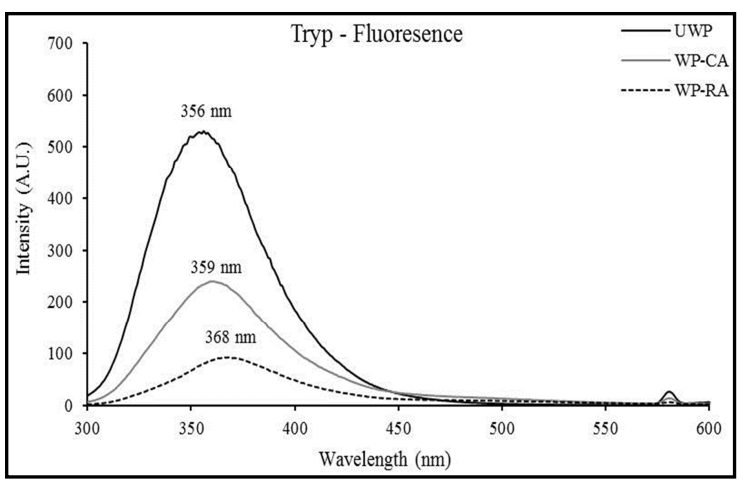

Figure 1. Tryptophan fluorescence scans of whey protein isolate modified with rosmarinic and chlorogenic acids. Where: UWP; unmodified protein, WP-CA; modified WP with chlorogenic acid and WP-RA; modified WP with rosmarinic acid.

The changes in the hydrophilic/hydrophobic character of proteins using RP-HPLC

The surface activity of proteins is one of the main character in many functional applications of proteins, e.g. foaming and emulsification. The alterations in the hydrophilic/hydrophobic character of the WP-CA and WPRA in the comparison with unmodified WP protein can be clarified by the alteration in the retention times of the main peak using RP-HPLC (Figure 2). The RP-HPLC chromatograms showed that the WP comprises two major components, the first one is $\alpha$-lactalbumin ( $\alpha$-LA), which elutes at $\sim 10.8 \mathrm{~min}$ and the second one is $\beta$-lactoglobulin ( $\beta$ LG) with two variants (B and A), which elute at $\sim 19.5$ and $20 \mathrm{~min}$, respectively. These observations are in agreement with those of Keppler et al. (2017) and Ali et al. (2018). After the modification, new shoulders at low retention times $\sim 10.2 \mathrm{~min}$ and (between 16.5 and $18.5 \mathrm{~min}$ ) were noted for $\alpha$-LA and two variants of $\beta$-LG modified with CA and RA, respectively. For $\beta$-LG, the presenting of numerous new peaks which elute between 16.5 and $18.5 \mathrm{~min}$, clearly displays that the protein has many binding sites for oxidized CA and RA. Moreover, the intensity of main peaks ( $\alpha-\mathrm{LA}$ and $\beta$-LG) of modified WP was decreased compared to unmodified WP (Figure 2). The explanation for this change is that the proteins hydrophobicity relates with the number and disposition of polar groups and the covalent bound of the CA and RA to WP causes the blocking of the hydrophilic groups of amino groups of protein, in contrary there is also an increase in the number of both a polar and polar groups, which involved in bound phenolic compounds.

\section{The change in UV - vis spectra of proteins}

In parallel to the change in tryptophan fluorescence and RP-HPLC data, the covalently modified WP with CA and RA can be also studied by the change in UV-vis spectra of them compared to unmodified one (Ali et al. 2012, Liu et al. 2015, Karefyllakis et al. 2018). Therefore, the absorbance of free CA and RA and WP, WP-CA and WP-RA conjugates were recorded at the range of wavelength between 190 to $600 \mathrm{~nm}$ and the results are presented in the Figure (3). Free CA and RA showed a peak with maximum absorbance between 325 and $330 \mathrm{~nm}$. As it appeared in the same figure, all protein soultions showed a peak with maximum absorbance at $280 \mathrm{~nm}$, which are related to amino acids tyrosine and tryptophan of protein (Karefyllakis et al. 2018). In addition to this peak, the WP-CA and WP-RA conjugates showed new shoulders in UV-vis spectra at the maximum of absorption between 325 and $330 \mathrm{~nm}$. While, this shoulder is not found in unmodified WP. These results are in agreement with those of Ali et al. (2012), Liu et al. (2015) and Karefyllakis et al. (2018).This observation supports the results of RP-HPLC method. Figure (3) showed also that the absorbance of modified proteins was affected with the type of phenolic acids used, where the WP-RA conjugate showed the highest UV absorbance compared to WP-CA.

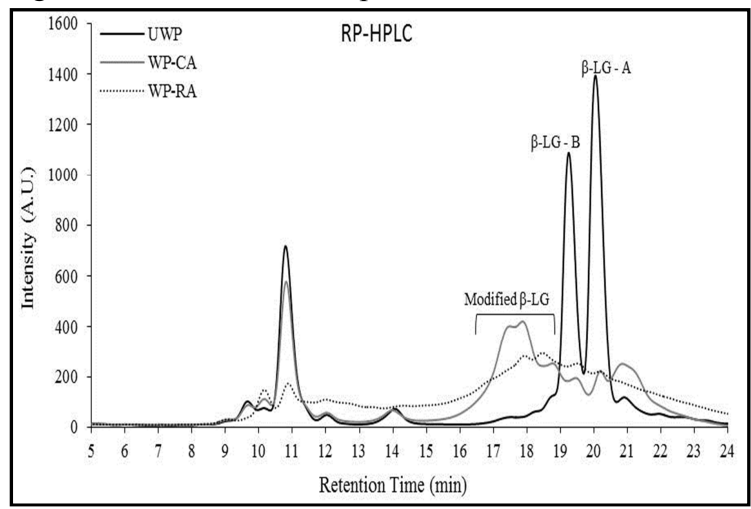

Figure 2. RP-HPLC of proteins modified with rosmarinic and chlorogenic acids. Where: UWP; unmodified protein, WP-CA; modified WP with chlorogenic acid and WP-RA; modified WP with rosmarinic acid.

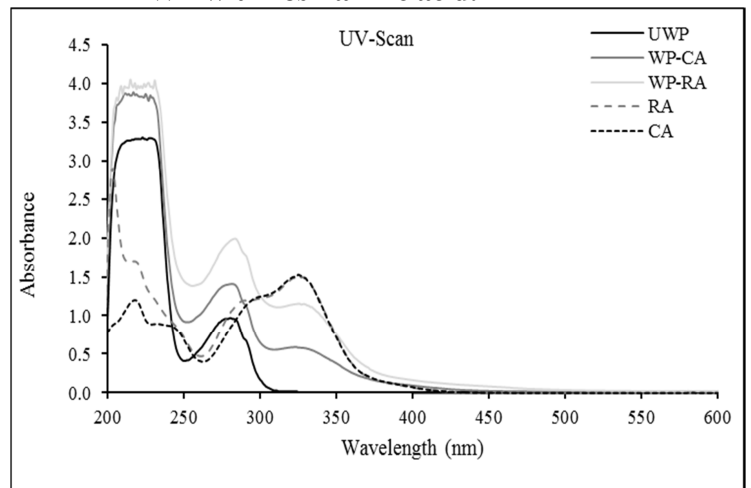

Figure 3. UV/Vis spectra of whey protein isolate modified with rosmarinic and chlorogenic acids. Where: UWP; unmodified protein, WP-CA; modified WP with chlorogenic acid and WP-RA; modified WP with rosmarinic acid.

The change in molecular weight of proteins using ESITOF-MS analysis

The changes in molecular weight of WP protein after incubation with CA and RA for $24 \mathrm{~h}$ were studied using the LC-ESI-TOF-MS technique and the results are recognized in Figure $4 \mathrm{~A}$ and $\mathrm{B}$. The ESI-TOF- mass spectra of unmodified and modified WP shows the two major $\beta$-LG protein variants present in almost all equimolar ratios, according to signal intensities, the signals at charge state +17 at m/z 1076.1112 (variant B) and m/z 1081.1680 (variant A). Deconvolution of the signals leads to an average protein mass of $18276.99 \mathrm{Da}$ for variant $\mathrm{B}$, and for variant $\mathrm{A}$, an average mass of 18362.45 $\mathrm{Da}$ was calculated. These results are in the line with values 
mentioned by others (Keppler et al. 2014, Wilde et al. 2016). Moreover, another two minor peaks with mass 18602 and $18687 \mathrm{Da}$, which are related to minor glycosylation of two variant of $\beta-\mathrm{LG}$, respectively were detected. This observation is similar to data published by Hau and Bovetto (2001) and Gzerwenka et al. (2006). After the modification of WP with CA and RA, new peaks were detected (Figure 4 A and B),

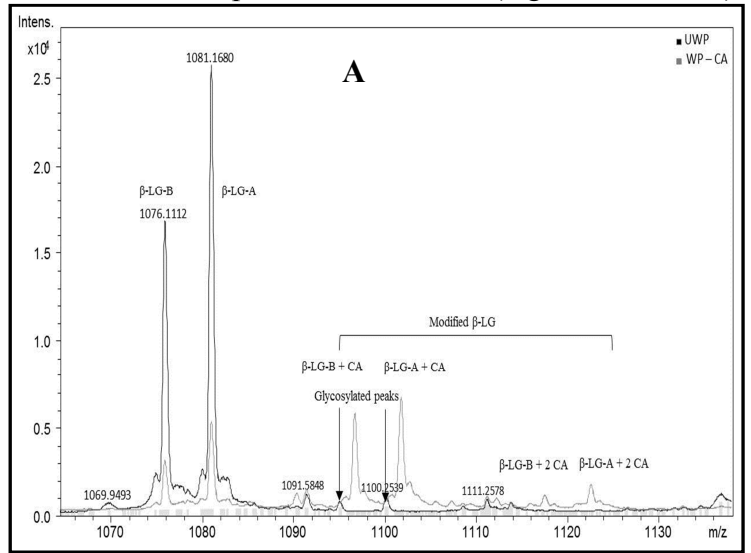

which could account for addition of one molecule of CA (353 Da) and two molecules of CA (705 Da) and one molecule RA (358 Da) to both $\beta$-LG protein variants, respectively. These results could be explained by the oxidation of CA and RA and form reactive quinone which covalently attached to protein. These results are in agreement with Prigent et al. (2007) and Ali et al. (2013).

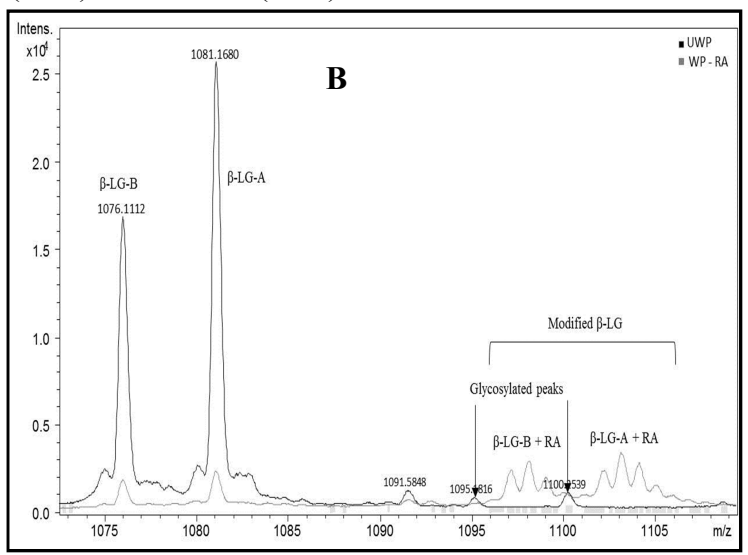

Figure 4. ESI-MS of proteins modified with chlorogenic acid (A) and rosmarinic acid (B). Where: UWP; unmodified protein, WP-CA; modified WP with chlorogenic acid and WP-RA; modified WP with rosmarinic acid.

\section{Antioxidant activities of whey proteins}

The antioxidant activities of unmodified WP and WP-CA and WP-RA conjugates were determined using TEAC assay and the results are shown in Figure (5). It could be found that the antioxidant activity of WP significantly increased (at $\mathrm{p} \leq 0.05$ ) after incubating for $24 \mathrm{~h}$ at alkaline conditions with CA and RA. These results are in full agreement with previous studies (Ali et al. 2013, Ali et al. 2018). Unmodified WP showed low activity (52.65 $\mu \mathrm{M}$ TE/g protein), while, the WP-CA and WP-RA conjugates showed 4 and 6.8 fold higher antioxidant activities, where the values were 214 and $359 \mu \mathrm{M}$ TE/g protein, respectively. These data show that the covalent attachment of CA and RA to WP could strongly improve the stability of products by scavenge the radicals and end the radical chain reaction. Therefore, WP-CA and WP-RA conjugates could be used in food applications as effective antioxidants. For example, improvement of antioxidant activity of whey protein by RA improved the antimicrobial activity as recently reported by Ali et al. (2018).

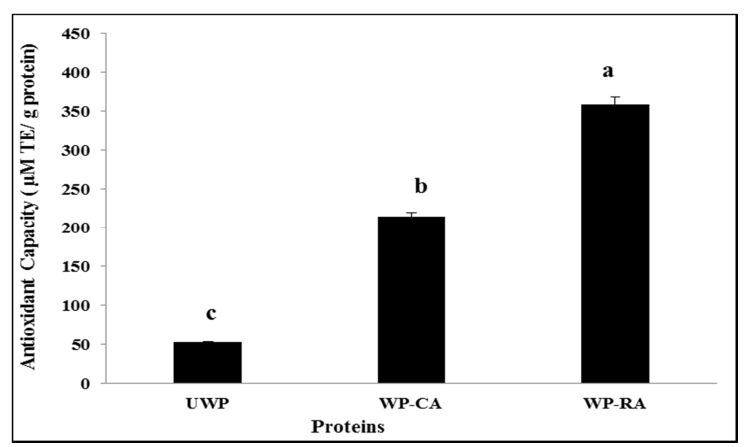

Figure 5. Antioxidant activities of whey protein isolate modified with chlorogenic and rosmarinic acids. Where: UWP; unmodified protein, WPCA; modified WP with chlorogenic acid and WP-RA; modified WP with rosmarinic acid.
Induction of systemic resistance against Tobacco mosaic virus by modified proteins

Effects of modified proteins on disease severity and virus accumulation

The typical severe symptoms of Tobacco mosaic virus (TMV) in tomato plants involved mosaic and deformed leaves, and established in the control after 14 days of inoculation. The results of disease severity displayed that the unmodified whey proteins (UWP), modified with chlorogenic acid (WP-CA) and modified with rosmarinic acid (WP-RA) treatments significantly decreased disease occurrence and disease severity when compared to pathogen control (Table 2). Disease severity values were significantly lower in WP-CA and WP-RA treatments compared with WP treatment. The ELISA data (Table 2) showed that treatments with WP-CA or WP-RA resulted in significantly lower amounts of TMV compared to the pathogen control at two weeks post inoculation. The present results of greenhouse bioassay revealed that whey protein treatments reduced the mosaic symptoms and decreased the virus accumulation in tobacco. This results are in agreement with those of Abdelbaki et al. (2010), who reported that whey protein fractions can be used for controlling the TYLCV-infected plants. Additionally, Milk components such as salts and amino-acids were found to be effective in controlling powdery mildew and other diseases (Mcgrath and Shishkoff 1999).

Effects of unmodified and modified whey protein treatments on defense enzymes

The bioassay on defense enzymes (peroxidase POD and polyphenoloxidase PPO) showed that the treatment with unmodified whey protein (WP) induced higher accumulation of enzymes in tobacco leaves, while a much greater amount of proteins were recorded in modified protein with cholorogenic acid (WP-CA) or modified with rosmarinic acid (WP-RA) treatments compared to plants 
challenge inoculated with pathogen (Table 3). In the assay of POD, treatment with WP-RA showed the highest activities followed by WP-RA and WP treated plants. In the assay of PPO, the enzyme activities in modified whey protein treatments were significantly higher than unmodified protein treatment (Table 3). POD may strengthen the cell wall which stands as a barrier against pathogen attack. Moreover, PPO oxidizes phenolic compounds into quinones, which inhibit virus by inactivating viral RNA. Recent studies have also reported that the induction of peroxidase and polyphenoloxidase enzymes by application of different inducers could reinforce the plants against viruses, for example Tomato spotted wilt virus (Kandan et al. 2005).

Table 2. Disease severity and TMV accumulation in upper non-inoculated leaves of tomato plants treated with WP, WP-CA and WP-RA at 2 weeks after virus inoculation.

\begin{tabular}{lcc}
\hline Treatment & $\begin{array}{c}\text { Disease severity } \\
\text { of TMV }\end{array}$ & $\begin{array}{c}\text { Detection of TMV by } \\
\text { ELISA (405 nm) }\end{array}$ \\
\hline UWP & $3.6 \pm 0.8^{\mathrm{b}}$ & $0.67 \pm 0.13^{\mathrm{b}}$ \\
WP-RA & $1.9 \pm 0.6^{\mathrm{c}}$ & $0.39 \pm 0.07^{\mathrm{c}}$ \\
WP-CA & $2.0 \pm 0.5^{\mathrm{c}}$ & $0.43 \pm 0.09^{\mathrm{c}}$ \\
Control & $5.3 \pm 0.9^{\mathrm{a}}$ & $1.03 \pm 0.19^{\mathrm{a}}$ \\
\hline
\end{tabular}

Statistical comparisons were completed between treatments within a single column. The different letters represent significant differences using Fisher's LSD test at $\boldsymbol{P} \leq \mathbf{0 . 0 5}$. Where: UWP; unmodified protein, WP-CA; modified WP with chlorogenic acid and WP-RA; modified WP with rosmarinic acid

Table 3. Effects of WP, WP-CA and WP-RA on defense enzymes and PR proteins in tomato Peroxidase (POD) and Polyphenol oxidase (PPO) at $48 \mathrm{hrs}$ after virus challenge inoculation.

\begin{tabular}{lcc}
\hline Treatment & $\begin{array}{c}\text { POD activity } \\
\left.\text { (Units } \boldsymbol{\mu g}^{-1} \mathbf{F W}\right)\end{array}$ & $\begin{array}{c}\text { PPO activity } \\
\left(\text { Units } \boldsymbol{\mu g}^{-1} \mathbf{F W}\right)\end{array}$ \\
\hline UWP & $450^{\mathrm{c}}$ & $820^{\mathrm{c}}$ \\
WP-RA & $690^{\mathrm{a}}$ & $1270^{\mathrm{a}}$ \\
WP-CA & $610^{\mathrm{b}}$ & $1145^{\mathrm{b}}$ \\
Control & $211^{\mathrm{d}}$ & $335^{\mathrm{d}}$ \\
\hline
\end{tabular}

Statistical comparisons were made among treatments within a single column. The different letters represent significant differences using Fisher's LSD test at $\boldsymbol{P} \leq \mathbf{0 . 0 5}$.

Effect of unmodified and modified whey protein treatments on the relative expression of $P R 1$ gene

Obtained results revealed a significant $(P \leq 0.05)$ increase of $P R 1$ gene expression level in WP, WP-CA and WP-RA treated tomato plants as compared to control (Figure 6). Plants treated with WP-CA and WP-RA showed the highest expression values (33.06), (34.03) as compared to non-treated plants (3.55), repectively. Although several studies demonstrated antimicrobial activity of whey protein, nevertheless, its mode of action against plant viruses, still remain unknown. It is well recognized that PR proteins are included in plant defense and often worked as a good marker for induced resistance. Penicillium simplicissimum elicited induced systemic resistance against Cucumber mosaic virus in tobacco and Arabidopsis via the expression of pathogensis-related genes especially PRI (Elsharkawy et al. 2012).

$P A L$ gene expression level was significantly increased in plants treated with unmodified and modified whey proteins as compared to control. In all groups, plants treated with WP-RA (20.07) showed significant higher expression than other treatments. Moreover, treatment with WP-RA resulted in higher up-regulation of PAL gene expression than UWP treated plants (Figure 7). PAL is a key enzyme of phenylpropanoid metabolism containing the synthesis of several secondary metabolites for example phenylpropanoids, phenols, and monomers of lignin and salicylic acid. The accumulation of such secondary compounds is involved in plant immunity and related with induced resistance (Harish et al. 2008).

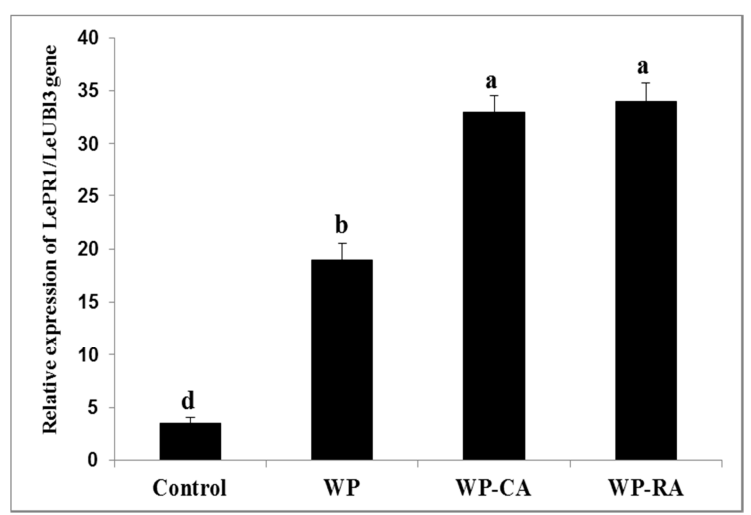

Figure 6. The expression of PR1 gene in tomato plants in control group, UWP; unmodified protein, WP-CA; modified WP with chlorogenic acid and WP-RA; modified WP with rosmarinic acid treatments using real-time quantitative PCR analysis.

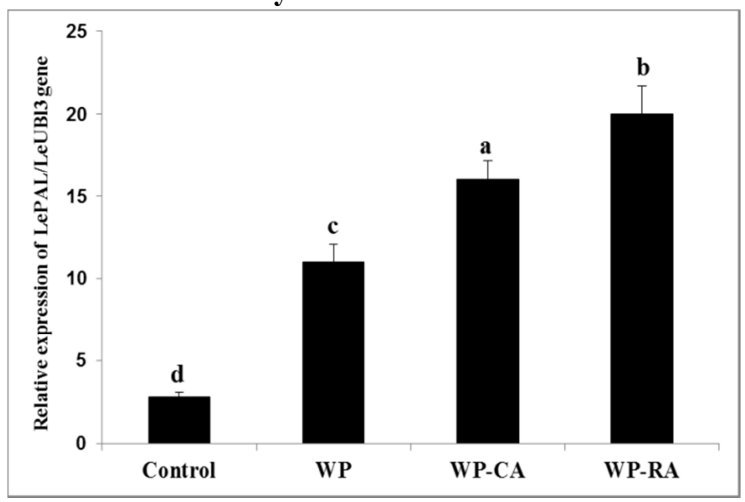

Figure 7. The expression of PAL gene in tomato plants in control group, UWP; unmodified protein, WP-CA; modified WP with chlorogenic acid and WP-RA; modified WP with rosmarinic acid treatments using real-time quantitative PCR analysis.

Antiviral activities of unmodified and modified whey proteins against TMV

Significantly fewer necrotic lesions showed in plants treated with mixture of virus inoculum and WP-RA and WP-CA than the control. The number of necrotic lesions was approximately 125 and 140, respectively. The unmodified whey protein (WP) treated leaves had a significant decrease in the number of lesions with 240 compared with the control (Figure 8). Numerous studies related with the antiviral activity of native and modified whey proteins in human (Pan et al. 2006, Chobert et al. 2007). Other studies concentrated on the usage of milk or milk constituents to control plant viruses (Liakot et al. 
2001). The action of antiviral proteins such as lactoferrin with receptors on cell surface and/or with viral envelope proteins is critical to blocking viral entry to target cells. The charge of antiviral protein plays a main role in this interaction. Chemical modifications lead to changes in the charges of milk proteins, which can improve their antiviral properties (Waarts et al. 2005).

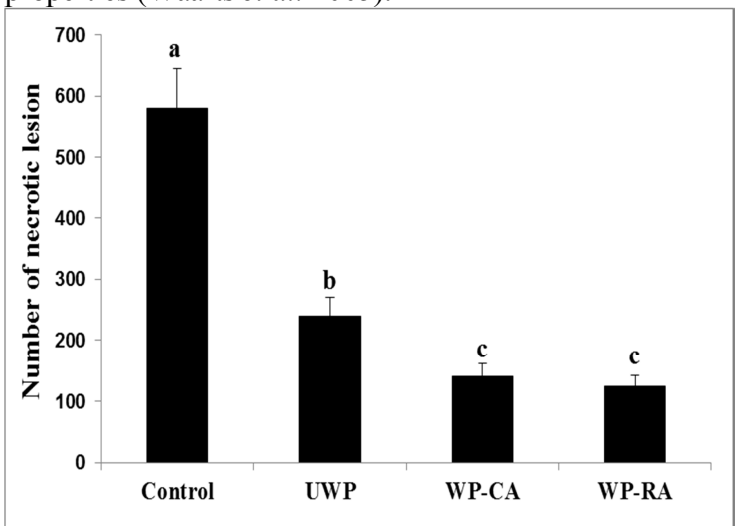

Figure 8. Number of necrotic lesions in tobacco plants treated with UWP; unmodified protein, WPCA; modified WP with chlorogenic acid and WP-RA; modified WP with rosmarinic acid and infected with Tobacco mosaic virus (TMV). The number of necrotic lesions was determined at 6th days post-inoculation. Bars mean values obtained from five plants \pm SD.

\section{CONCLUSION}

The covalent modification between whey protein isolate and chlorogenic acid and rosmarinic acid, at alkaline condition ( $\mathrm{pH} \mathrm{9)}$, in the presence of air and at room temperature, changed the structure of modified proteins compared to unmodified one. Rosmarinic acid showed highly reaction compared to chlorogenic acid. ESI-MS data is good evidence to the covalent attachment of phenolics to proteins. Moreover, the modification improved the antioxidant activity of proteins. Therefore, we can recommend that modified proteins (WP-CA and WP-RA) could be used as functional foods because the trends of consumers are shifting towards new health-promoting ingredients. Moreover, these proteins may provide adequate protection against TMV as alternative methods for pesticide. The application becomes particularly interesting since polyphenol -enriched extracts may be obtained from several agroindustrial by-products.

\section{REFERENCES}

Abd El-Maksoud, A. A.; Abd El-Ghany, I. H.; El-Beltagi, H. S.; Anankanbil, S.; Banerjee, C.; Petersen, S. V.; Pérez, B. and Guo, Z. (2018). Adding functionality to milk-based protein: Preparation, and physicochemical characterization of $\beta$-lactoglobulinphenolic conjugates. Food Chem., 241, 281-289.

Abdelbacki, A. M.; Taha, S. H.; Sitohy, M. Z.; Dawood, A. I. A.; Hamid, M. M. A.-E. and Rezk, A. A. (2010). Inhibition of Tomato Yellow Leaf Curl Virus (TYLCV) using whey proteins. Virol. J., 7, 26.
Ahmed, M.; Henson, D. A.; Sanderson, M. C.; Nieman, D. C.; Gillitt, N. D. and Lila, M. A. (2014). The Protective Effects of a Polyphenol-Enriched Protein Powder on Exercise-Induced Susceptibility to Virus Infection. Phytother Res, 28, 1829-1836.

Ali, M.; Homann, T.; Khalil, M.; Kruse, H.-P. and Rawel, H. (2013). Milk Whey Protein Modification by Coffee-Specific Phenolics: Effect on Structural and Functional Properties. J. Agric. Food Chem., 61, 6911-6920.

Ali, M.; Homann, T.; Kreisel, J.; Khalil, M.; Puhlmann, R.; Kruse, H.-P. and Rawel, H. (2012). Characterization and Modeling of the Interactions between Coffee Storage Proteins and Phenolic Compounds. J. Agric. Food Chem., 60, 1160111608.

Ali, M.; Keppler, J. K.; Coenye, T. and Schwarz, K. (2018). Covalent Whey Protein - Rosmarinic Acid Interactions: A Comparison of Alkaline and Enzymatic Modifications on Physicochemical, Antioxidative, and Antibacterial Properties. J. Food Sci., 83, 2092-2100.

Bongartz, V.; Brandt, L.; Gehrmann, M.; Zimmermann, B.; Schulze-Kaysers, N. and Schieber, A. (2016). Evidence for the Formation of Benzacridine Derivatives in Alkaline-Treated Sunflower Meal and Model Solutions. Molecules, 21, 91.

Bucci, L. and Unlu, L. (Eds.) (2000). Proteins and amino acid supplements in exercise and sport, Boca Raton, FL, USA, CRC Press.

Cao, Y. and Xiong, Y. L. (2017). Interaction of Whey Proteins with Phenolic Derivatives Under Neutral and Acidic pH Conditions. J. Food Sci., 82, 409419.

Chobert, J.; Sitohy, M.; Billaudel, S.; Michele, D. and Haertle, T. (2007). Anticytomegaloviral activity of esterified milk proteins and L-Polylysines. $\mathrm{Mol}$ Microbiol Biotechnol, 13, 255-258.

Czerwenka, C.; Maier, I.; Pittner, F. and Lindner, W. (2006). Investigation of the Lactosylation of Whey Proteins by Liquid Chromatography - Mass Spectrometry. J. Agric. Food Chem., 54, 88748882.

Dalbem Rocha, L.; Costa Monteiro, M. and Teodoro, A. J. (2012). Anticancer Properties of Hydroxycinnamic Acids -A Review. Cancer and Clinical Oncology, 1, 4858-4866. .

Elsharkawy, M. M. and El-Sawy, M. M. (2015). Control of Bean common mosaic virus by plant extracts in bean plants. Int. J. Pest Manage., 61, 54-59.

Elsharkawy, M. M. and Mousa, K. M. (2015). Induction of systemic resistance against Papaya ring spot virus (PRSV) and its vector Myzus persicae by Penicillium simplicissimum GP17-2 and silica (Sio2) nanopowder. Int. J. Pest Manage. , 61, 353358.

Elsharkawy, M. M.; Shimizu, M.; Takahashi, H. and Hyakumachi, M. (2012). Induction of systemic resistance against Cucumber mosaic virus by Penicillium simplicissimum GP17-2 in Arabidopsis and tobacco. Plant Pathol, 61, 964-76 
Elsharkawy, M. M.; Shimizu, M.; Takahashi, H.; Ozaki, K. and Hyakumachi, M. (2013). Induction of systemic resistance against Cucumber mosaic virus in Arabidopsis thaliana by Trichoderma asperellum SKT-1. Plant Pathol. J. , 29, 193-200.

Gan, J.; Chen, H.; Liu, J.; Wang, Y.; Nirasawa, S. and Cheng, Y. (2016). Interactions of $\beta$--Conglycinin (7S) with Different Phenolic Acids - Impact on Structural Characteristics and Proteolytic Degradation of Proteins. Int. J. Mol. Sci., 17, 1671.

Gillian, F. (2005) Milk as a mangment tool for virus diseases.

Grace, M. H.; Guzman, I.; Roopchand, D. E.; Moskal, K.; Cheng, D. M.; Pogrebnyak, N.; Raskin, I.; Howell, A. and Lila, M. A. (2013). Stable Binding of Alternative Protein-enriched Food Matrices with Concentrated Cranberry Bioflavonoids for Functional Food Applications. J. Agric. Food Chem., 61, 6856-6864.

Hall, W. L.; Millward, D. J.; Long, S. J. and Morgan, L. M. (2003). Casein and whey exert different effects on plasma amino acid profiles, gastrointestinal hormone secretion and appetite. Br. J. Nutr., 89, 239-248.

Harish, S.; Kavino, M.; Kumar, N.; Saravanakumar, D.; Soorianathasundaram, K. and Samiyappan, R. (2008). Biohardening with Plant Growth Promoting Rhizosphere and Endophytic Bacteria Induces Systemic Resistance against Banana bunchy top virus',. Applied Soil Ecology, 39, 187-200.

Hau, J. R. and Bovetto, L. (2001). Characterisation of modified whey protein in milk ingredients by liquid chromatography coupled to electrospray ionisation mass spectrometry. J. Chromatogr. A, 926, 105-112.

Jia, Z.; Zheng, M.; Tao, F.; Chen, W.; Huang, G. and Jiang, J. (2016). Effect of covalent modification by (-)-epigallocatechin-3-gallate on physicochemical and functional properties of whey protein isolate. LWT-Food Sci Technol, 66, 305-310.

Kandan, A.; Ramiah, M.; Vasanthi, V. J.; Radjacommare, R.; Nandakumar, R.; Ramanathan, A. and Samiyappan, R. (2005). Use of Pseudomonas fluorescens-based Formulations for Management of Tomato spotted wilt virus (TSWV) and Enhanced Yield in Tomato. Biocontrol Science and Technology, 15, 553569.

Karefyllakis, D.; Salakou, S.; Bitter, J. H.; Van Der Goot, A. J. and Nikiforidis, C. V. (2018). Covalent Bonding of Chlorogenic Acid Induces Structural Modifications on Sunflower Proteins. Chem Phys Chem, 19, 459-468.

Keppler, J. K.; Koudelka, T.; Palani, K.; Stuhldreier, M. C.; Temps, F.; Tholey, A. and Schwarz, K. (2014). Characterization of the covalent binding of allyl isothiocyanate to $\beta$-lactoglobulin by fluorescence quenching, equilibrium measurement, and mass spectrometry. J. Biomol. Struct. Dyn., 32, 1103-1117.

Keppler, J. K.; Martin, D.; Garamus, V. M.; BertonCarabin, C.; Nipoti, E.; Coenye, T. and Schwarz, K. (2017). Functionality of whey proteins covalently modified by allyl isothiocyanate. Part 1 physicochemical and antibacterial properties of native and modified whey proteins at $\mathrm{pH} 2$ to 7. Food Hydrocoll, 65, 130-143.
Krissansen, G. W. (2007). Emerging Health Properties of Whey Proteins and Their Clinical Implications. $J$ Am Coll Nutr, 26, 713S-723S.

Li, B. J. and Li, F. Y. (1998). Changes in Activities and Eletrophretic Patterns of Peroxidase and Polyphenoloxidase in Cucumbers during Infection with Cladosporium cucumerinum'. Scientia Agricultura Sinica, 31, 86-88.

Liakot, M.; Asad, D.; Pramanik, B. and Ashrafuzzaman, M. (2001). Management of leaf curl disease of Tomato. . Pakistan. J Biolo Science, 4, 1512-1514.

Lian, L.; Xie, L.; Zheng, L. and Lin, Q. (2011). Induction of systemic resistance in tobacco against Tobacco mosaic virus by Bacillus spp. . Biocontrol Sci. Technol.,, 21, 281-292.

Liu, F.; Sun, C.; Wang, D.; Yuan, F. and Gao, Y. (2015). Glycosylation improves the functional characteristics of chlorogenic acid-lactoferrin conjugate. RSC Advances, 5, 78215-78228.

Madureira, A. R.; Pereira, C. U. I.; Gomes, A. M. P.; Pintado, M. E. and Xavier Malcata, F. (2007). Bovine whey proteins - Overview on their main biological properties. Food Res Int, 40, 1197-1211.

Mcgrath, M. and Shishkoff, N. (1999). Evaluation of biocompatible products for managing cucurbit powdery mildew. Crop Prot, 18, 471-478.

Meng, S.; Cao, J.; Feng, Q.; Peng, J. and Hu, Y. (1996). Roles of chlorogenic acid on regulating glucose and lipids metabolism: a review, Evid. Based Complement. Phytochemistry, 42, 1551-1555.

Meng, S.; Cao, J.; Feng, Q.; Peng, J. and Hu, Y. (2013). Roles of chlorogenic acid on regulating glucose and lipids metabolism: a review, Evid. Based Complement. Alternat. Med.

Niggeweg, R.; Michael, A. J. and Martin, C. (2004). Engineering plants with increased levels of the antioxidant chlorogenic acid. Nat. Biotechnol. , 22, 746-754.

Onakpoya, I. J.; Spencer, E. A.; Thompson, M. J. and Heneghan, C. J. (2015). The effect of chlorogenic acid on blood pressure: a systematic review and meta-analysis of randomized clinical trials. J. Hum. Hypertens, 29, 77-81.

Pan, Y.; Lee, A.; Wan, J.; Coventry, M.; Michalsk, W.; Shiell, B. and Roginski, H. (2006). Antiviral properties of milk proteins and peptides (A Review). International Dairy J., 1252-1261.

Prigent, S. P. V. E.; Gruppen, H.; Visser, A. J. W. G.; Van Koningsveld, G. A.; De Jong, G. A. H. and Voragen, A. G. J. (2003). Effects of Non-covalent Interactions with 5-O-Caffeoylquinic Acid (Chlorogenic Acid) on the Heat Denaturation and Solubility of Globular Proteins. J. Agric. Food Chem., 51, 5088-5095.

Prigent, S. V. E.; Voragen, A. G. J.; Visser, A. J. W. G.; Van Koningsveld, G. A. and Gruppen, H. (2007). Covalent interactions between proteins and oxidation products of caffeoylquinic acid (chlorogenic acid). Journal of the Science of Food and Agriculture, 87, 2502-2510. 
Rawel, H. and Rohn, S. (2010). Nature of hydroxycinnamate-protein interactions. Phytochem Rev, 9, 93-109.

Rawel, H. M.; Kroll, J. and Rohn, S. (2001). Reactions of phenolic substances with lysozyme-physicochemical characterisation and proteolytic digestion of the derivatives. Food Chem., 72, 5971.

Rawel, H. M.; Meidtner, K. and Kroll, J. (2005). Binding of selected phenolic compounds to proteins. $J$. Agric. Food Chem., 53, 4228-35.

Rawel, H. M.; Rohn, S.; Kruse, H.-P. and Kroll, J. R. (2002). Structural changes induced in bovine serum albumin by covalent attachment of chlorogenic acid. Food Chem., 78, 443-455.

Re, R.; Pellegrini, N.; Proteggente, A.; Pannala, A.; Yang, M. and Rice-Evans, C. (1999). Antioxidant activity applying an improved ABTS radical cation decolorization assay. Free Radical Biology and Medicine, 26, 1231-1237.

Rohn, S.; Rawel, H. M.; Röber, M. and Kroll, J. (2005). Reactions with phenolic substances can induce changes in some physico-chemical properties and activities of bromelain - the consequences for supplementary food products. Int $J$ Food Sci Technol, 40, 771-782.

Roopchand, D. E.; Kuhn, P.; Krueger, C. G.; Moskal, K.; Lila, M. and Raskin, I. (2013). Concord Grape Pomace Polyphenols Complexed to Soy Protein Isolate Are Stable and Hypoglycemic in Diabetic Mice. J. Agric. Food Chem., 61(47), 11428-11433.

Shetty, R.; Fretté, X.; Jensen, B.; Shetty, N. P.; Jensen, J. D.; Jørgensen, H. J.; Newman, M. A. and Christensen, L. P. (2011). Silicon-induced changes in antifungal phenolic acids, flavonoids, and key phenylpropanoid pathway genes during the interaction between miniature roses and the biotrophic pathogen Podosphaera pannosa,. Plant Physiol., 157, 2194-2205.
Solak, B. B. and Akin, N. (2012). Functionality of Whey Protein. Int J Health Nutr 3, 1-7.

Spizzirri, U. G.; Iemma, F.; Puoci, F.; Cirillo, G.; Curcio, M.; Parisi, O. I. and Picci, N. (2009). Synthesis of Antioxidant Polymers by Grafting of Gallic Acid and Catechin on Gelatin. Biomacromolecules, 10, 1923-1930.

Sung, W. and Lee, D. G. (2010). Antifungal action of chlorogenic acid against pathogenic fungi. Pure Appl. Chem., 82, 219-226.

Waarts, B.; Aneke, O.; Smit, J.; Kimata, K.; Bittman, R. and Meijer, D. (2005). Antiviral activity of human lactoferrin: Inhibition of alphavirus interaction with heparan sulfate. Virology Journal, 333, 284-292.

Walzem, R. L.; Dillard, C. J. and German, J. B. (2002). Whey Components: Millennia of Evolution Create Functionalities for Mammalian Nutrition: What We Know and What We May Be Overlooking. Crit. Rev. Food Sci. Nutr., 42, 353-375.

Wang, S.; Wu, H.; Qiao, J.; Ma, L.; Liu, J.; Xia, Y. and Gao, X. (2009). Molecular mechanism of plant growth promotion and induced systemic resistance to Tobacco mosaic virus by Bacillus spp. . $J$. Microbiol. Biotechnol., 19, 1250-1258.

Wang, X. K. (2006) Principles and Techniques of Plant Physiological Biochemical Experiment (2nd ed.) ed. Beijing, Higher Education Press, pp. 224225.

Wilde, S. C.; Treitz, C.; Keppler, J. K.; Koudelka, T.; Palani, K.; Tholey, A.; Rawel, H. M. and Schwarz, K. (2016). $\beta$-Lactoglobulin as nanotransporter Part II: Characterization of the covalent protein modification by allicin and diallyl disulfide. Food Chem., 197, 1022-1029.

You, J.; Luo, Y. and Wu, J. (2012). Conjugation of Ovotransferrin with Catechin Shows Improved Antioxidant Activity. J. Agric. Food Chem., 62, 2581-2587.

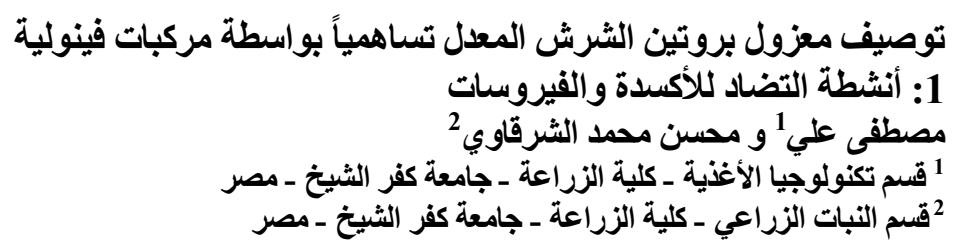

على الرغم من أن التعديل التساهمي للبروتينات مع المركبات الفينولية قد وجد حالبًا جهودًا كبيرة ، إلا أن تطبيقات البروتينات المعدلة

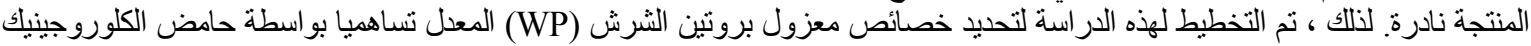

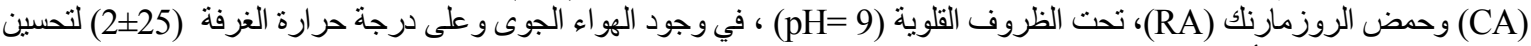

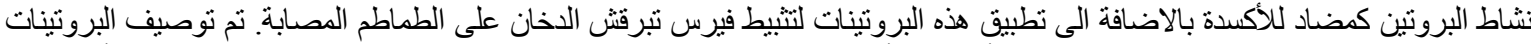

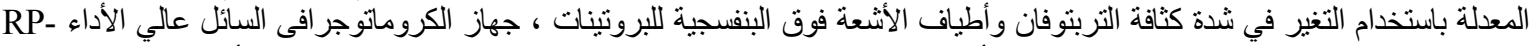

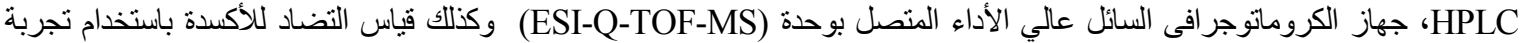

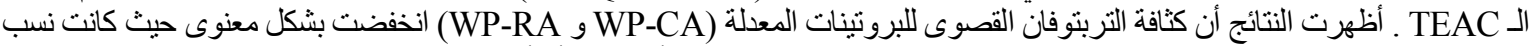

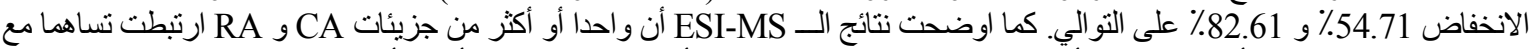

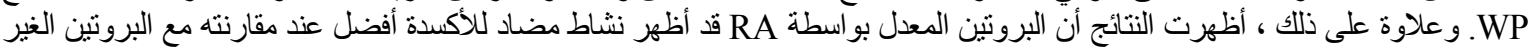

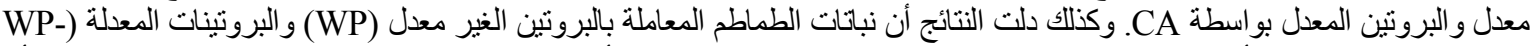

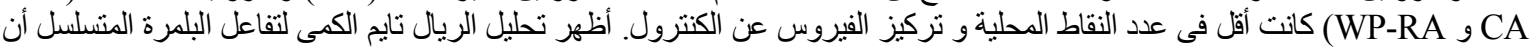

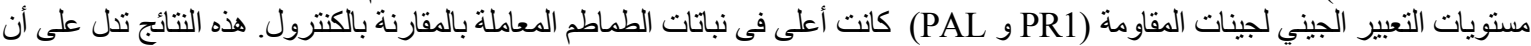

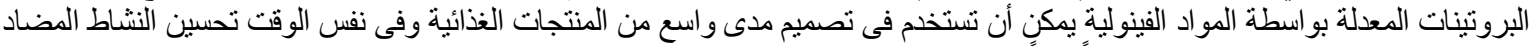

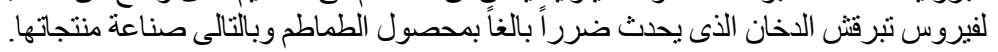

